\title{
ELECTROLESS NICKEL PLATING: BATH CONTROL
}

\author{
R. Tenno, K. Kantola, H. Koivo \\ Helsinki University of Technology, Control Engineering Laboratory, \\ P.O. Box 5400, FIN-02015 Espoo, Finland
}

\begin{abstract}
In this paper, bath control is proposed for the electroless nickel plating through holes board process. The main parameters of the product (board) - thickness of the plating film and phosphorous content - are stabilized at constant levels using optimal tracking control. The set point for control is calculated from the model in dependence on the current state of the process. The $\mathrm{pH}$-index and nickel percentage are stabilised at timevariable set points using simple feed-forward PI-control that is robust to the loading perturbation. Copyright (C) 2005 IFAC
\end{abstract}

Keywords: control, modelling, chemical industry.

\section{INTRODUCTION}

Electroless nickel plating is an established process in many industries: electronics, oil and gas industry, motor industry, machinery, etc. Usually, it does not require advanced control like it does in microelectronics (e.g. board, microprocessor), where electrically isolated contactors are a few microns thin and packed close to each other. They are created using precise plating technology that makes control obligatory.

The purpose of this paper is to propose controls for stabilisation of the thickness and phosphorous content of plating film at desired levels.

The thickness and phosphorous content are the prime parameters of nickel plating, but unfortunately, unobservable. They can be analysed in laboratory with a delay of about 10 hours, which is too long for effective control. A better method is to evaluate these parameters from a model in dependence on the current state and apply them for calculation of the electrochemically balanced tracking trajectory, which is the target for control of the $\mathrm{pH}$-index and nickel percentage.

An adequate plating process model should be applied to evaluate the control target. Such model was developed in (Tenno, et al., 2004) for the electroless nickel plating through holes (PTH) board process as a modified model of Kim, Sohn (1996) and other authors (Bindra and White, 1990; Ramasubramanian, et al., 1999) investigating the reaction mechanism (Mallory, 1990; Salvago and Gavallotti 1972) and the discharge mechanism (Newman and Tiedeman, 1975; Tiedeman and Newman, 1979; Gu, et al., 1987).

Electroless nickel plating is a highly disturbed process by the bath loading, which is a finite-state Markov process. It will be shown that the proposed control is capable of eliminating this perturbation.

\section{MODEL}

The model (Tenno, et al., 2004) for PTH board process is modified for control in this section. It was developed for the following anodic and cathodic reactions.

Anodic reaction - hypophosphite oxidation

$\mathrm{H}_{2} \mathrm{PO}_{3}^{-}+2 \mathrm{H}^{+}+2 \mathrm{e}^{-} \stackrel{\leftrightarrow}{\longleftrightarrow} \mathrm{H}_{2} \mathrm{PO}_{2}^{-}+\mathrm{H}_{2} \mathrm{O}, \mathrm{U}_{1}=-0.504 \mathrm{~V}$

Cathodic reactions - phosphorous deposition, hydrogen gas evolution, nickel deposition 


$$
\begin{aligned}
\mathrm{H}_{2} \mathrm{PO}_{2}{ }^{-}+2 \mathrm{H}^{+}+\mathrm{e}^{-} & \mathrm{P}+2 \mathrm{H}_{2} \mathrm{O}, \mathrm{U}_{2}=-0.391 \mathrm{~V} \\
2 \mathrm{H}^{+}+2 \mathrm{e}^{-} & \longleftrightarrow \mathrm{H}_{2}, \quad \mathrm{U}_{3}=0 \mathrm{~V} \\
\mathrm{Ni}^{2+}+2 \mathrm{e}^{-} & \longleftrightarrow \mathrm{Ni}, \quad \mathrm{U}_{4}=0.257 \mathrm{~V}
\end{aligned}
$$

In these reactions, the hydrogen ion formation exceeds consumption and $\mathrm{pH}$-index is balanced with ammonia

$$
\mathrm{NH}_{3}+\mathrm{H}_{2} \mathrm{O} \rightleftarrows \mathrm{NH}_{4}^{+}+\mathrm{OH}^{-}
$$

The discharge reaction controls the deposition process mainly; it can be represented as a cell model.

\subsection{Cell Model}

Electrode reaction. The current densities of the electrochemical reactions (1)-(4) can be represented as a two-directional process in a model, which is mainly the anodic reaction model for oxidation and the cathodic reaction model for others

$$
\mathrm{i}_{\mathrm{n}}=\mathrm{i}_{0 \mathrm{n}} \mu_{\mathrm{n}}\left\{\exp \left(v \alpha_{\mathrm{an}} \mathrm{p}_{\mathrm{n}} \mathrm{k} \eta_{\mathrm{n}}\right)-\exp \left(-v \alpha_{\mathrm{cn}} \mathrm{p}_{\mathrm{n}} \mathrm{k} \eta_{\mathrm{n}}\right)\right\},
$$

where

$\mathrm{n}$ - reaction number: 1 - oxidation, 2 - $\mathrm{P}$ deposition, 3

- hydrogen evolution, 4 - Ni deposition,

$\mathrm{i}_{\mathrm{n}}$ - current density, $\mathrm{A} / \mathrm{cm}^{2}$,

$\mathrm{i}_{0 \mathrm{n}}$ - exchange current density, $\mathrm{A} / \mathrm{cm}^{2}$,

$$
\mathrm{i}_{01}=18, \mathrm{i}_{02}=0.5, \mathrm{i}_{03}=2.5, \quad \mathrm{i}_{04}=1.6 \mathrm{~mA} / \mathrm{cm}^{2},
$$

$\eta_{\mathrm{n}}$ - overpotential, $\eta_{\mathrm{n}}=\phi-\mathrm{v}_{\mathrm{n}}$,

$\phi$ - mixed potential, $\mathrm{V}$,

$\mathrm{V}_{\mathrm{n}}$ - thermodynamic equilibrium potential, $\mathrm{V}$,

$\mu_{n}$ - dimensionless concentration of species,

$v$ - robustness coefficient, 0.1 ,

$\mathrm{k}$ - temperature voltage, $\mathrm{k}=\mathrm{F} / \mathrm{RT}, 1 / \mathrm{V}$,

$\mathrm{T}$ - temperature, $\mathrm{K}$,

$\mathrm{R}$ - universal gas constant, $8.3145 \mathrm{~J} / \mathrm{mol}-\mathrm{K}$,

F - Faraday's constant, $96487 \mathrm{C} / \mathrm{mol}$,

$\mathrm{p}_{\mathrm{n}}$ - number of exchanged electrons, $\mathrm{p}_{\mathrm{n}}=2, \mathrm{p}_{2}=1$,

$\alpha_{a n}$ - anodic apparent transfer coefficients, $\alpha_{a n}+\alpha_{c n}=1$,

$\alpha_{c n}$ - cathodic apparent transfer coefficients,

$$
\alpha_{a 1}=0.53, \alpha_{c 2}=0.62, \alpha_{c 3}=0.59, \alpha_{c 4}=0.47 .
$$

The anodic current density is equal to the sum of cathodic current densities because of the continuity

$$
\mathrm{i}_{1}+\mathrm{i}_{2}+\mathrm{i}_{3}+\mathrm{i}_{4}=0 .
$$

The mixed potential is a measured parameter in [1]; here it is adjusted to satisfy (7) irrespective to any change in the partial reactions as in a real process where it is adjusted by the deposition process itself to maintain the charge conservation requirement irrespective to any changes in the concentrations or equilibrium potentials.

Equilibrium potential. The equilibrium potentials of the partial reactions can be evaluated from the Nernst equation using unit activity for solid material (deposed nickel and phosphorous) and water, and unit partial pressure (1 atm) of hydrogen as follows

$$
\begin{gathered}
\mathrm{v}_{1}=\mathrm{U}_{1}+\kappa\left(\log \mathrm{c}_{5}-\log \mathrm{c}_{1}-2 \mathrm{pH}\right), \\
\mathrm{v}_{2}=\mathrm{U}_{2}+0.2 \kappa\left(\log \mathrm{c}_{1}-2 \mathrm{pH}\right), \\
\mathrm{v}_{3}=\mathrm{U}_{3}-2 \kappa \mathrm{pH}, \\
\mathrm{v}_{4}=\mathrm{U}_{4}+\kappa \log \mathrm{c}_{4},
\end{gathered}
$$

where $\kappa^{-1}=2 \mathrm{k} \log$ e,

$c_{i}$ - ion concentration of species ( $c_{1}$ - hypophosphite, $c_{2}$ - orthophosphite or $\mathrm{c}_{4}$ - nickel), $\mathrm{mol} / \mathrm{dm}^{3}$.

\subsection{Plating}

The deposition process can be decomposed in two independent processes - in nickel and phosphorous deposition - and composed by superposition of these processes in calculation of the Ni-P-alloy film $x_{a}=$ $\mathrm{x}_{\mathrm{Ni}}+\mathrm{x}_{\mathrm{P}}$.

$$
\frac{d x_{N i}}{d t}=-i_{4} \frac{M_{N i}}{2 F \rho_{N i}}, \quad \frac{d x_{P}}{d t}=-i_{2} \frac{M_{P}}{F \rho_{P}},
$$

where

$\mathrm{t}$ - immersion time, sec,

$\mathrm{x}_{\mathrm{Ni}}$ - partial thickness of nickel, cm; physically, this is a ratio between volume of nickel and plate area, $\mathrm{X}_{\mathrm{P}}$ - partial thickness of phosphorous, $\mathrm{cm}$, $x_{a}$ - thickness of the Ni-P-alloy film, cm,

$\mathrm{i}_{4}$ - current density of nickel deposition reaction, $\mathrm{A} / \mathrm{cm}^{2}$, $\mathrm{i}_{2}$ - current density of phosphorous deposition reaction, $\mathrm{A} / \mathrm{cm}^{2}$, $\mathrm{M}_{\mathrm{Ni}}$ - molecular weight of nickel, $58.7 \mathrm{~g} / \mathrm{mol}$, $\mathrm{M}_{\mathrm{P}}$ - molecular weight of phosphorous, $31 \mathrm{~g} / \mathrm{mol}$, $\rho_{\mathrm{Ni}}$ - nickel density, $8.9 \mathrm{~g} / \mathrm{cm}^{3}$.

$\rho_{\mathrm{P}}$ - phosphorous density, $1.82 \mathrm{~g} / \mathrm{cm}^{3}$.

The phosphorous content in the Ni-P-alloy film can be expressed as the volumetric ratio between the overall and partial thickness $\mathrm{P}_{\mathrm{vol}}=\left(\mathrm{x}_{\mathrm{P}} / \mathrm{x}_{\mathrm{a}}\right) 100 \%$ or as the weight ratio $\mathrm{P}_{\mathrm{wt}}$ between the overall and partial weights.

\subsection{Concentration Dynamics}

Feeding and utilisation of fresh reagents along with formation of the by-products induces coupled changes of the concentrations of species (Tenno, et al., 2004). 


\section{Hypophosphite feeding and consumption}

$\mathrm{dc}_{1}=\left[\mathrm{A}\left(2 \mathrm{i}_{2}-\mathrm{i}_{1}\right) / 2 \mathrm{~F}+\mathrm{Q}_{1 \mathrm{f}} \mathrm{c}_{1 \mathrm{f}}\right] \mathrm{dt}+\sigma_{1} \mathrm{dW}, \mathrm{c}_{1}\left(\mathrm{t}_{0}\right)=\mathrm{c}_{1 \mathrm{ref}}$,

where

$\mathrm{c}_{1}$ - hypophosphite concentration, $\mathrm{mol} \mathrm{H}_{2} \mathrm{PO}_{2}{ }^{-} / \mathrm{dm}^{3}$,

$\mathrm{c}_{1 \mathrm{f}}$ - feeding solution concentration, $\mathrm{mol} \mathrm{H}_{2} \mathrm{PO}_{2}{ }^{-} / \mathrm{dm}^{3}$,

$\mathrm{Q}_{1 \mathrm{f}}$ - hypophosphite dilution rate, 1/s,

$\mathrm{t}_{0}$ - makeup moment for a newly made bath, sec,

$\mathrm{t}$ - elapsed time, sec,

$\sigma_{1}-$ model inaccuracy,

$\mathrm{W}$ - model-prediction error: Wiener process.

Nickel feeding and consumption

$$
\mathrm{dc}_{4}=\left[\mathrm{Ai}_{4} / 2 \mathrm{~F}+\mathrm{Q}_{4 \mathrm{f}} \mathrm{c}_{4 \mathrm{f}}\right] \mathrm{dt}+\sigma_{4} \mathrm{dW}, \mathrm{c}_{4}\left(\mathrm{t}_{0}\right)=\mathrm{c}_{4 \mathrm{ref}},
$$

where

$\mathrm{c}_{4}$ - nickel concentration, $\mathrm{mol} \mathrm{Ni} \mathrm{N}^{2+} / \mathrm{dm}^{3}$,

$\mathrm{c}_{4 \mathrm{f}}$ - feeding concentration, $\mathrm{mol} \mathrm{Ni} \mathrm{Ni}^{2+} / \mathrm{dm}^{3}$,

$\mathrm{Q}_{4 \mathrm{f}}$ - nickel dilution rate, $1 / \mathrm{s}$.

Hydrogen formation and removal with ammonia

$\mathrm{dc}_{3}=\left[\mathrm{A}\left(\mathrm{i}_{1}+2 \mathrm{i}_{2}+\mathrm{i}_{3}\right) / \mathrm{F}\right] \mathrm{dt}-\mathrm{dx}+\sigma_{3} \mathrm{dW}, \mathrm{c}_{3}\left(\mathrm{t}_{0}\right)=\mathrm{c}_{3 \mathrm{ref}}$,

where

$c_{3}$ - hydrogen concentration, $\mathrm{mol} \mathrm{H}^{+} / \mathrm{dm}^{3}$,

$\mathrm{dx}$ - dissociation-consumed hydrogen, $\mathrm{mol} \mathrm{H}^{+} / \mathrm{dm}^{3}$.

The following approximation is used for control

where

$$
\mathrm{dx}=\mathrm{Q}_{3 \mathrm{f}} \mathrm{c}_{3 \mathrm{f}} \mathrm{dt},
$$

$c_{3 \mathrm{f}}$ - feeding concentration, $\mathrm{mol} \mathrm{NH} / \mathrm{dm}^{3}$,

$\mathrm{Q}_{3 \mathrm{f}}$ - ammonia dilution rate, $1 / \mathrm{s}$.

It is valid for a steady-state process of ammonia feeding and consumption. In general, the process (15) is smoother and slightly delayed with respect to the feeding process (16). Thus, a control developed based on this approximation (16) should be limited by a special requirement of smooth ammonia pumping if compared to nickel pumping.

Accumulation and evolution of the by-products can be represented as follows.

\section{Orthophosphite accumulation}

$$
\mathrm{dc}_{2}=\mathrm{Ai}_{1} \mathrm{dt} / 2 \mathrm{~F}+\sigma_{2} \mathrm{dW}, \quad \mathrm{c}_{2}\left(\mathrm{t}_{0}\right)=0
$$

$\mathrm{c}_{2}$ - orthophosphate concentration, $\mathrm{mol} \mathrm{H}_{2} \mathrm{PO}_{3}{ }^{-} / \mathrm{dm}^{3}$.

\section{Hydrogen gas evolution}

$$
\mathrm{dc}_{5}=-\mathrm{Ai}_{3} \mathrm{dt} / 2 \mathrm{~F}+\sigma_{5} \mathrm{dW},
$$

$\mathrm{dc}_{5} / \mathrm{dt}$ - hydrogen evolution rate, $\mathrm{mol} \mathrm{gH}_{2} / \mathrm{s} / \mathrm{dm}^{3}$.
The Wiener processes are introduced to show the model inaccuracy that should be accounted for in development of the estimation and control strategy insensitive to uncertainty.

\subsection{Loading Process}

The bath loading is defined as a total metal area of plates immersed in the solution per bath volume. For stable plating this parameter should be kept in the range of $0.3-1.5 \mathrm{dm}^{2} / \mathrm{dm}^{3}$, preferably in between 0.5 1.0 .

$$
\mathrm{A}=\mathrm{A}_{\mathrm{P} Z}
$$

where

A - bath loading, $\mathrm{cm}^{2} / \mathrm{dm}^{3}$

$\mathrm{z}$ - loading level, $\mathrm{z}=\mathrm{Z} / \mathrm{N}$,

$\mathrm{Z}$ - state of loading,

$\mathrm{N}$ - maximum number of baskets (rack for plates) in use, $\mathrm{N}=3$,

$A_{P}$ - maximum loading for all baskets immersed (a product constant), $\mathrm{cm}^{2} / \mathrm{dm}^{3}$.

The state of bath loading is equal to the number of baskets immersed. For single basket $Z=1$ means that it is immersed, otherwise $Z=0$. For three baskets, $Z$ $=2$ means that two baskets are immersed and there is a free place in the bath for the third basket to be immersed.

The state loading is a finite-state Markov process defined by the down loading rate up and up loading rate; it is considered as a completely observable process in this paper.

\subsection{Measurements}

Typically two analysers are used in a plating process control as standard equipment.

Nickel analyser. Analysis is described by

where

$$
\xi_{4}=10^{3}\left(\mathrm{c}_{4}+\mathrm{r}_{4} \varepsilon\right)
$$

$\xi_{4}$ - measured nickel percentage: $100 \%$ is equal to

$0.1 \mathrm{~mol} \mathrm{Ni}^{+2} / \mathrm{dm}^{3}$,

$\mathrm{c}_{4}$ - nickel concentration, $\mathrm{mol} \mathrm{Ni}{ }^{+2} / \mathrm{dm}^{3}$,

$\mathrm{r}_{4}$ - analysis accuracy,

$\varepsilon$ - analysis error: standard Gaussian variable.

pH analyzer. Analysis is described by

where

$$
\xi_{3}=10^{-\mathrm{pH}}=\mathrm{c}_{3}+\mathrm{r}_{3} \varepsilon,
$$

$\xi_{3}$ - measured hydrogen concentration; measured $\mathrm{pH}$ index is equal to $\mathrm{pH}=-\log \xi_{3}$, $\mathrm{c}_{3}$ - hydrogen ion concentration, $\mathrm{mol} \mathrm{H}^{+} / \mathrm{dm}^{3}$, $r_{3}$ - analysis accuracy. 
Beside these online analyses the flow rates of nickel, hypophosphite and ammonia are also analysed.

The hypophosphite concentration is analyzed in laboratory in every 6 hours. The missing measurements may be extrapolated.

The orthophosphite concentration can be estimated by the metal turn over measured online.

The hypo- and orthophosphite concentrations are considered as a completely observable process in this paper.

\section{CONTROL TARGET}

The geometrical and physical properties of PTHboard are defined with several parameters. Among them, the thickness of Ni-P-alloy film and phosphorous content are crucial. In plating process they are controlled through choice of references for $\mathrm{pH}$-index and nickel percentage. These parameters can be kept constant using adjusted ammonia and nickel feeding rates. The stabilization process, being completely automatic, is somewhat controversial, with heuristic choice of the references. This choice is based on the laboratory analysis with essential delay. The film thickness is measured twice per day in X-rayfluorescence spectroscopy. The phosphorus content is rarely evaluated.

The desired thickness of Ni-P-alloy film is a constant equal to the central point of the admissible range $\mathrm{x}_{\mathrm{a}}=$ $4 \mu \mathrm{m}$ and the desired phosphorous content is a constant: $\mathrm{P}_{\mathrm{wt}}=8.5 \%$. The partial thicknesses of nickel and phosphorous can be calculated as target values for control from the desired thickness and phosphorous content

$$
\mathrm{x}_{\mathrm{Ni}}{ }^{*}=\mathrm{x}_{\mathrm{a}}-\mathrm{x}_{\mathrm{P}}{ }^{*}, \quad \mathrm{x}_{\mathrm{P}}{ }^{*}=\mathrm{x}_{\mathrm{a}} \mathrm{P}_{\mathrm{vol}} / 100 .
$$

These target values can be achieved in practice if they are balanced. This means that the $\mathrm{pH}$-index, nickel percentage and mixed potential should satisfy the charge conservation requirement (7) involving the electrode reactions (6) and the thermodynamic equilibrium potentials (9)-(12). It also includes the deposition rate (12) and target (22) requirements, coupled in this relationship

$$
-\frac{\mathrm{i}_{4}}{\mathrm{C}_{\mathrm{Ni}}}=\frac{\mathrm{x}_{\mathrm{Ni}}{ }^{*}}{\tau}, \quad-\frac{\mathrm{i}_{2}}{\mathrm{C}_{\mathrm{P}}}=\frac{\mathrm{x}_{\mathrm{P}}{ }^{*}}{\tau},
$$

where

$\mathrm{x}_{\mathrm{Ni}}{ }^{*}$ - target thickness of nickel, cm,

$\mathrm{x}_{\mathrm{P}}{ }^{*}$ - target thickness of phosphorous, $\mathrm{cm}$,

$\tau$ - plating time (22 $\mathrm{min}$ ), $\mathrm{s}$,

$\mathrm{C}$ - charge density of $\mathrm{Ni}-$ and $\mathrm{P}$-ions, $\mathrm{C} / \mathrm{cm}^{3}$.

Numerical minimisation of the function $\mathrm{f}=\mathrm{f}\left\{\mathrm{i}\left(\mathrm{c}_{3}, \mathrm{c}_{4}, \phi\right)\right\}$
$\mathrm{f}=\left(\mathrm{i}_{1}+\mathrm{i}_{2}+\mathrm{i}_{3}+\mathrm{i}_{4}\right)^{2}+\left(\mathrm{i}_{2}-\mathrm{C}_{\mathrm{P}} \frac{\mathrm{x}_{\mathrm{P}}^{*}}{\tau}\right)^{2}+\left(\mathrm{i}_{4}-\mathrm{C}_{\mathrm{Ni}} \frac{\mathrm{x}_{\mathrm{Ni}}{ }^{*}}{\tau}\right)^{2}(24)$

is the simplest method for calculation of the balanced processes for the hydrogen and nickel concentration and for the mixed potential. The target values are coupled processes (meaning implicit use of the mixed potential); they depend on the hypo- and orthophosphate concentrations

$$
\zeta_{3}=\mathrm{c}_{3}\left(\mathrm{c}_{1}, \mathrm{c}_{2}\right), \quad \zeta_{4}=\mathrm{c}_{4}\left(\mathrm{c}_{1}, \mathrm{c}_{2}\right), \quad \phi=\phi\left(\mathrm{c}_{1}, \mathrm{c}_{2}\right)
$$

The plating process is well controllable as long as the relationship between the target values holds. Otherwise an automatic change of the mixed potential takes place, affecting all reactions. Unfortunately, this change always takes place, even if the $\mathrm{pH}$-index and nickel percentage are kept constant. The hypoand orthophosphite concentrations are never constant - besides feeding, they depend on the utilization and consumption rates. The orthophosphate consumption, similar to the metal turn over, characterises the process of bath aging.

Therefore, the thickness and phosphorous content can be maintained at the desired levels through stabilization of the $\mathrm{pH}$-index and nickel percentage at certain time-varying levels. This tracking control problem is solved as follows.

\section{TRACKING CONTROL}

The tracking control problem can be approximately solved as a minimum variance problem. The model (14), (15) is linear in state and control variables for fixed current densities and nonlinear for free current densities; however depends weakly on the state variables through the almost invariant current densities. In this situation, the following feed-forward PIcontrol is justified and is a logical successor to the existing control in PTH board processes.

$$
u_{t}=A_{P} Z_{t} v-K_{p}\left[\xi_{t}-\zeta_{t}+T_{i}^{-1} \int_{0}^{t}\left(\xi_{s}-\zeta_{s}\right) d s\right]
$$

where

$\xi$ - measured hydrogen and nickel concentrations, $\xi=\left[\xi_{3}, \xi_{4}\right]^{\mathrm{T}}$,

$\zeta$ - target calculated from minimization of the criterion (24) as parameters $\zeta=\left[\zeta_{3}, \zeta_{4}\right]^{\mathrm{T}}$ dependent (25) on the hypo- and orthophosphite concentrations, $\mathrm{u}$ - controls: ammonia and nickel (hypophosphite) feeding rates, $\mathrm{u}=\left[\mathrm{Q}_{3 \mathrm{f}}, \mathrm{Q}_{4 \mathrm{f}}\right]^{\mathrm{T}}$,

$A_{P}$ - maximum loading,

$\mathrm{z}_{\mathrm{t}}$ - bath loading level (observable process),

$v$ - control setpoint for average bath loading,

$\mathrm{K}_{\mathrm{p}}$ - control gain: diagonal matrix of weights,

$\mathrm{T}_{\mathrm{i}}$ - integration time. 
This control depends on the model through the target. As a feed-forward control, it compensates for the bath loading change. This control is effective because of the following properties:

1. The applied tracking trajectory is relevant to the global target and to the current state of the process.

2. The state of bath loading switches controls (26) faster than its after-effect, observable through the $\mathrm{pH}$-index or nickel concentration.

3. Tracking of the nickel besides $\mathrm{pH}$-index allows separate control of the film thickness and phosphorous content. Their control is in disagreement if single parameter ( $\mathrm{pH}$-index) is applied as tracking control as done in practice.

\section{SIMULATION}

The proposed control (26) was tested in a series of simulation experiments one of them is described below. A large control effect will be shown on a demanding task formulated and solved as follows.

Control task. The initially low thickness $\mathrm{x}_{\mathrm{a}}=3.7 \mu \mathrm{m}$ and phosphorous $\mathrm{P}_{\mathrm{wt}}=7.8 \%$ must be corrected to the target values $\mathrm{x}_{\mathrm{a}}=4 \mu \mathrm{m}, \mathrm{P}_{\mathrm{wt}}=8.5 \%$ and then separately elevated $\mathrm{x}_{\mathrm{a}}=4.3 \mu \mathrm{m}$ and dropped down $\mathrm{P}_{\mathrm{wt}}=8.2 \%$ and finally recovered at the basic levels as shown in Figs 2, 3 .

Perturbation. The bath-loading process with strong effect on partial reactions was simulated as a Markov pure jump process shown in Fig. 1.

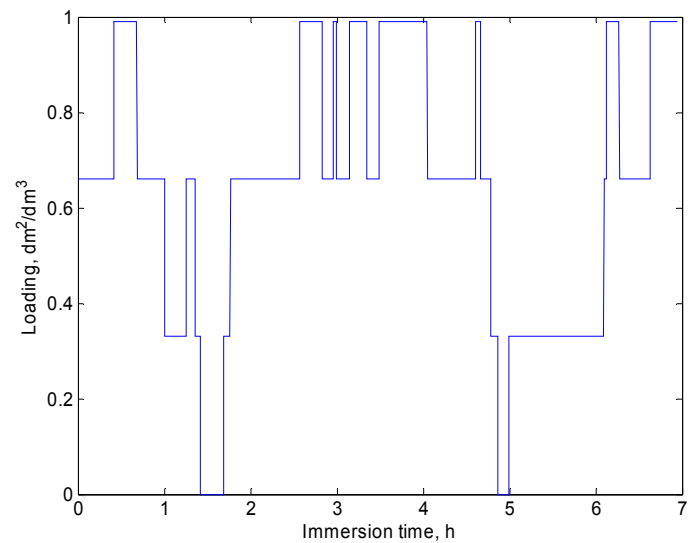

Fig. 1. Simulated bath-loading process.

Wiener processes were also introduced in every model to increase uncertainty; they were generated at relatively low level (5\% noise-to-signal ratio) to show the control effect clearly.

Tracking. Irrelevant to the perturbations introduced by the loading and Wiener processes, the plating film thickness and phosphorous content can be stabilised at the desired levels rather well (Figs 2, 3).

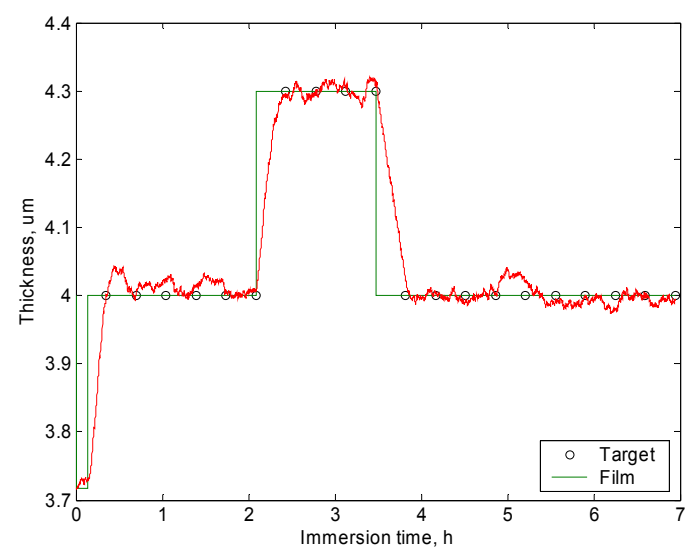

Fig. 2. Thickness of deposit, stabilised at target.

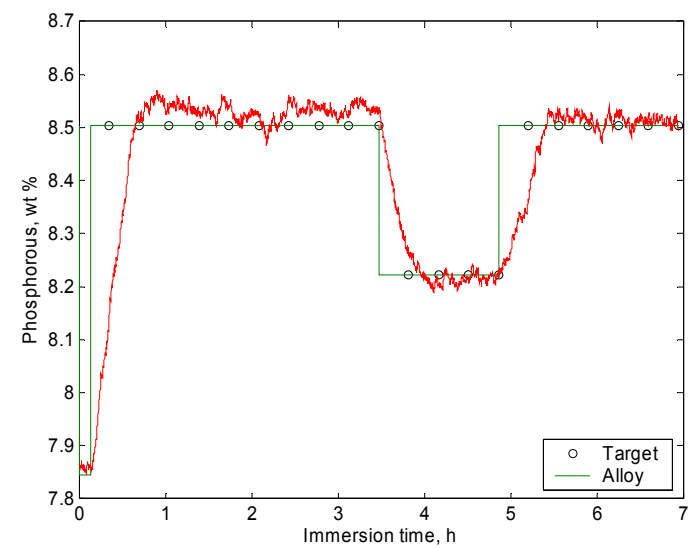

Fig. 3. Phosphorous content in alloy, stabilised at target.

The initial state correction is the largest one, it affects the deposition rates and rate-ratios (Fig. 4).

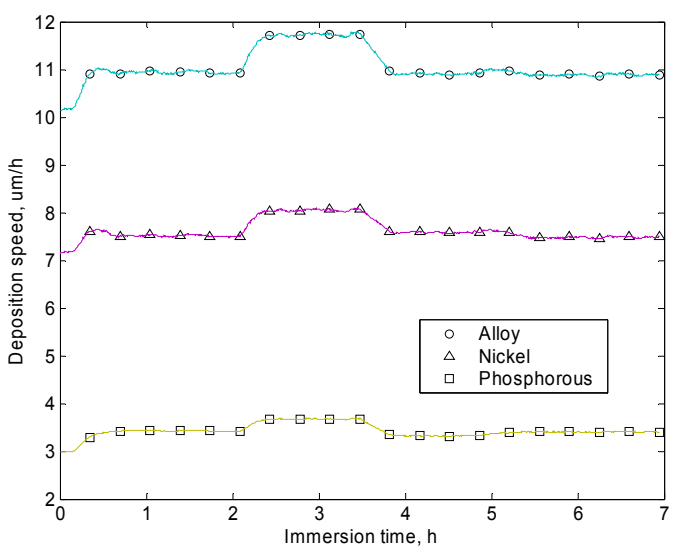

Fig. 4. Corrected deposition speed.

In the case of conventional PID control, variation is essentially large, because the desired $\mathrm{pH}$-index and nickel concentration are never balanced. To prevent unstable situations, a piecewise constant $\mathrm{pH}-$ trajectory is aimed for tracking in practice, while the nickel concentration level is aimed for keeping the level constant. 
The electrochemically balanced trajectories in Figs 5, 6 are relevant to the target values for thickness (Fig. 2) and phosphorous content (Fig. 3), and also to the current state of hypo- and orthophosphite concentrations and to the mixed potential.

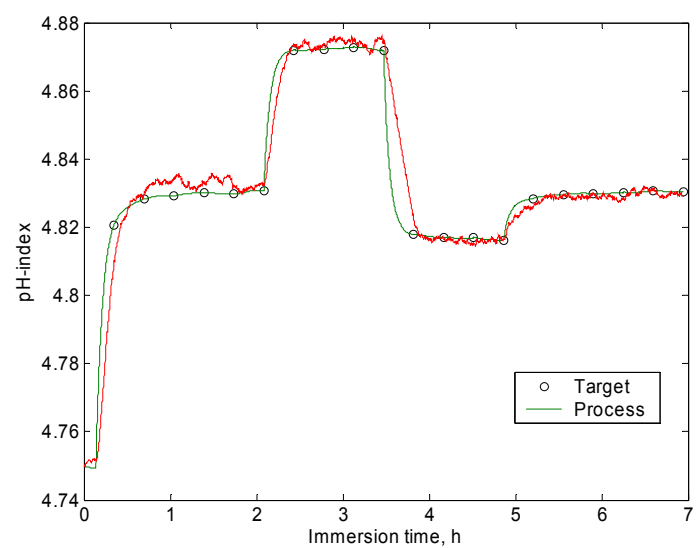

Fig. 5. Optimal $\mathrm{pH}$-index and its tracking in process control.

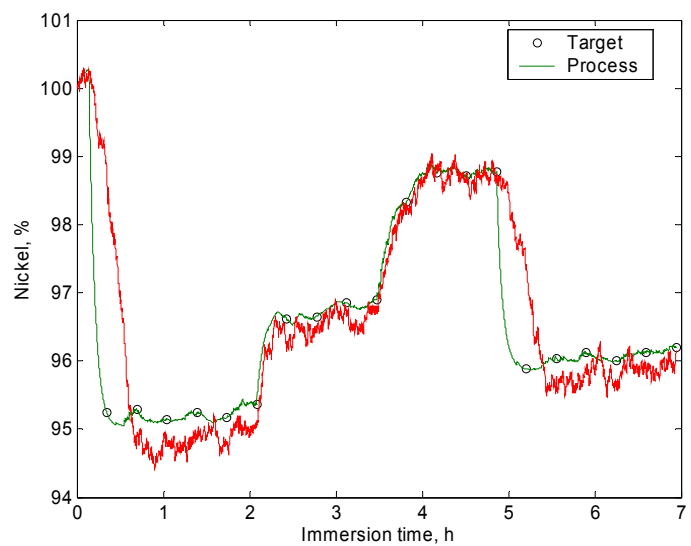

Fig. 6. Optimal nickel concentration and its tracking in process control.

Small changes to the feeding rates are required to stabilise the plating process, if correction is made in time and both flows are active controls as shown in Fig. 7.

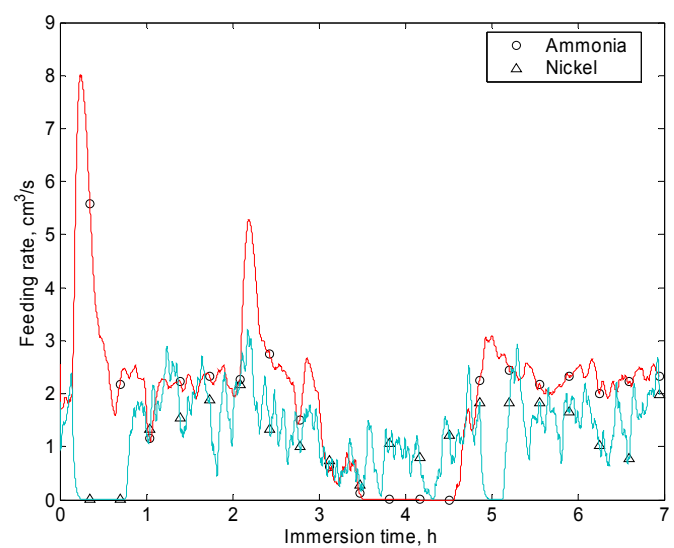

Fig. 7. Stabilizing controls.

More control is required if the process is stabilised with a single control (ammonia) or if the $\mathrm{pH}$-tracking trajectory is a piece-wise constant corrected 1-3 times during the lifetime of a bath.

\section{CONCLUSION}

It was shown that tracking control may improve the plating quality if

- the control target is evaluated as the electrochemically balanced target,

- the bath loading perturbation is eliminated by the feed-forward control,

- the pH-index and nickel percentage are both controlled.

\section{REFERENCES}

Bindra P. and J.R. White. Fundamental aspects of electroless copper plating in Electroless plating: fundamentals and applications. Ed. Mallory G.O., Hajdu J.B. AESF Society. Orlando. 1990. P. 290-329.

Gu H., Nguyen T.V. and R.E. White. A mathematical model of a lead-acid cell: Discharge, rest and charge. J. Electrochem. Soc. Vol 134, No 12. 1987. P. 2953-2960.

Kim Y.-S. and H.-J. Sohn. Mathematical modelling of electroless nickel deposition at steady state using rotating disk electrode. J. Electrochem. Soc. Vol 143, No 2. 1996. P. 505-509.

Mallory G.O. The fundamental aspects of electroless nickel plating in Electroless plating: fundamentals and applications. Ed. Mallory G.O., Hajdu J.B. AESF Society. Orlando. 1990. P. 1-56.

Newman J. and W.H. Tiedemann. Porous-electrode theory with battery applications. AIChE J. Vol 21, No 1. 1975. P. 25-41.

Ramasubramanian M., B.N. Popov, R.E. White and K.S. Chen. A mathematical model for electroless copper deposition on planar substrates. J. Electrochem. Soc. Vol 146, No 1. 1999. P. 111-116.

Salvago G. and P.L. Cavallotti. Characteristics of the chemical reduction of nickel alloys with hypophosphite. J. Vol, No . 1972. P. 665-671.

Tenno R., Kantola K., Koivo H. Electroless nickel plating: PCB process modelling and estimation. Proc. AIChE Annual Meeting. 2004. Austin, Texas. $12 \mathrm{p}$.

Tiedemann W.H. and J. Newman. in Battery Design and Optimization. S. Gross, Editor. The Electrochemical Society Softbound Proceeding Series, Princeton, New York. 1979. 23 p. 